\title{
Cyclin-Dependent Kinase 7
}

National Cancer Institute

\section{Source}

National Cancer Institute. Cyclin-Dependent Kinase 7. NCI Thesaurus. Code C89769.

Cyclin-dependent kinase 7 (346 aa, $\sim 39$ kDa) is encoded by the human CDK7 gene. This protein is involved in the mediation of protein phosphorylation that regulates both RNA polymerase II-mediated transcription and cell cycle progression. 